\title{
Belgeo
}

Revue belge de géographie

$1 \mid 2014$

From urban renewal to metropolitan strategies?

Cultural flagship projects in restructuring industrial areas

\section{Boris Grésillon, Géographie de l'art. Ville et création artistique}

Editions Economica, Paris, 2014

\section{Tatiana Debroux}

\section{CpenEdition}

\section{Journals}

Édition électronique

URL : http://journals.openedition.org/belgeo/12873

DOI : 10.4000/belgeo.12873

ISSN : 2294-9135

Éditeur :

National Committee of Geography of Belgium, Société Royale Belge de Géographie

Référence électronique

Tatiana Debroux, «Boris Grésillon, Géographie de l'art. Ville et création artistique », Belgeo [En ligne], 1 |

2014, mis en ligne le 15 décembre 2014, consulté le 22 septembre 2020. URL : http://

journals.openedition.org/belgeo/12873; DOI : https://doi.org/10.4000/belgeo.12873

Ce document a été généré automatiquement le 22 septembre 2020.

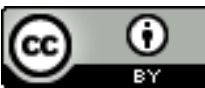

Belgeo est mis à disposition selon les termes de la licence Creative Commons Attribution 4.0 International. 


\section{Boris Grésillon, Géographie de l'art. Ville et création artistique}

Editions Economica, Paris, 2014

Tatiana Debroux

\section{RÉFÉRENCE}

Boris Grésillon, Géographie de l'art. Ville et création artistique, Editions Economica, Paris

En 2008, Boris Grésillon publiait un article important pour les chercheurs intéressés par les problématiques mêlant art et ville ; intégré à un numéro des Annales de géographie consacré à la géographie culturelle, l'article de Grésillon se distinguait par une volonté affirmée de positionnement en tant que géographie «de la culture $»^{1}$. Ce faisant, il se plaçait quelque peu en marge de la géographie culturelle telle qu'elle s'était développée depuis une vingtaine d'années autour de la figure tutélaire de Paul Claval qui, le premier, introduisit dans le champ français les travaux de la new cultural geography anglo-saxonne (à travers notamment la création de la revue Géographie et cultures). Déplorant l'absence de définition de cette sous-discipline géographique construite autour d'un objet très polysémique (la culture) ainsi qu'un manque d'explicitation des méthodes qui lui sont associées, le chercheur s'y essayait en prenant pour point de départ une acception étroite de la culture (l'art) et des réflexions entamées lors d'une thèse de doctorat portant sur la recomposition du paysage artistique et culturel berlinois depuis la réunification et sur le statut de métropole culturelle ${ }^{2}$.

Poursuivant son cheminement intellectuel, Grésillon vient de publier un ouvrage qui développe les arguments ébauchés en 2008, étendant son propos et l'illustrant à travers ses terrains de prédilection, Berlin et Marseille.

Organisé en deux parties et quatre chapitres, Géographie de l'art. Ville et création artistique dresse un état des lieux des développements de la géographie culturelle et de la position personnelle de l'auteur (partie " Positions »), avant d'éclairer cette dernière à travers quelques exemples choisis et une réflexion née du travail empirique sur les 
apports de la géographie à la compréhension des phénomènes artistiques (Partie « Terrains »).

4 Le livre est parcouru par trois fils rouges, déclinés au fil des chapitres : Comment l'art peut-il être appréhendé par les géographes et être pour eux un objet d'études adéquat? Comment situer la " géographie de l'art » au sein de la discipline et, plus largement, au sein des sciences de la ville? Comment la géographie peut-elle être utile aux artistes (et inversement)?

5 Décrivant l'essor et les raisons du succès de la géographie culturelle, ou plutôt, de la «nouvelle géographie culturelle» développée avec le tournant post-moderne des sciences sociales, le premier chapitre offre une synthèse bienvenue et nuancée des nombreux travaux qui s'en revendiquent. Cet état des lieux est d'autant plus intéressant qu'il est transnational, abordant les contextes et corpus scientifiques connus par l'auteur - géographies anglo-saxonne, française et allemande - et intégrant les nuances afférentes à des définitions variables du mot "culture» dans les trois langues envisagées.

6 En proposant «une lecture du fait culturel orientée vers les lieux de création, de production et de diffusion artistiques dans la ville »(p.7), Grésillon n'entend pas poser un nouveau sujet autonome, mais bien s'emparer de l'art (à travers ses lieux, ses acteurs et ses productions) comme d'un objet de recherches au croisement de la géographie culturelle, urbaine et sociale, rejetant ainsi les travers d'une géographie culturelle souvent trop culturaliste et dépolitisée.

7 Le deuxième chapitre donne à l'auteur l'occasion d'approfondir cette proposition; il s'agit sans conteste de la partie la plus originale et programmatique de l'ouvrage, offrant parfois par ses propositions le flanc à la critique (notamment en ce qui concerne le contenu des productions artistiques et leur réception, y compris par le chercheur peu pertinent ou trop ignoré, selon les points de vue).

8 Choisissant une définition restrictive de la culture, entendue au sens de création artistique, Boris Grésillon dépeint ce que peut être une géographie de l'art à travers l'étude de ses lieux et son inscription dans les débats théoriques contemporains. En effet, il ne s'agit pas seulement d'étudier la spatialité des lieux de création, de production, de représentation et de diffusion artistiques d'une entité géographique donnée, tant "off" qu'officiels; il convient d'envisager ces lieux comme des clefs de lecture de la géographie urbaine et d'interroger le rôle des acteurs du monde de l'art dans la fabrique urbaine.

9 "A partir du moment où l'on considère l'art comme un produit social, il est intéressant de se livrer à une étude complète des lieux d'art en analysant leur contenu, leur contenant et leur contexte. Enfin, considéré de la sorte, l'art devient un enjeu urbain et il s'articule avec les grandes questions urbaines, autrement dit avec les politiques d'aménagement et d'urbanisme, avec les stratégies de marketing urbain et d'image, avec l'économie culturelle, avec les enjeux sociaux» (p. 104). La partie que l'auteur consacre à distinguer la création de la créativité rappelle très justement combien derrière les mots se cachent des conceptions et des projets politiques divergents, débouchant sur des choix différents en matière de politique culturelle et/ou urbaine.

10 Partant sur le terrain, le chapitre $\mathbf{3}$ porte sur le couple art et territoire, à travers les propos et le travail de nombreux artistes rencontrés par Boris Grésillon. Comme l'auteur le souligne («L'espace, ce sont les artistes qui en parlent le mieux» (p. 156)), il 
est étonnant de constater la sensibilité accordée par ces artistes à leur environnement spatial et, plus encore, l'acuité avec laquelle ils en perçoivent les enjeux et la justesse (souvent géographiquement exacte!) avec laquelle ils le décrivent. Sans nul doute, ces propos peuvent éclairer le géographe et nourrir sa réflexion scientifique.

11 A côté des sources traditionnelles permettant d'appréhender les spatialités de l'art, peu nombreuses il est vrai, il importe pour Grésillon d'emprunter les chemins balisés par d'autres disciplines sœurs (notamment la sociologie de l'art) et d'oser une approche résolument qualitative, mêlant entretiens, presse et littérature grise sur la ville. $\mathrm{Ce}$ faisant, «Il ne s'agira pas, pour le géographe, de se débarrasser de son savoir, mais de l'utiliser différemment (...) le géographe de l'art n'oubliera pas de mettre en valeur deux élément essentiels : sa connaissance des phénomènes sociaux spatialement construits, et son savoir géographique » (p. 206). Le dernier chapitre du livre porte justement sur l'apport du géographe à la compréhension des phénomènes artistiques; en réalité, il envisage plus largement comment les savoirs et pratiques du géographe de l'art peuvent contribuer à la compréhension de phénomènes et projets urbains auxquels sont de plus en plus souvent associés les artistes.

12 Rédigé d'une plume limpide, l'ouvrage de Boris Grésillon apporte une synthèse utile des voies empruntées par la géographie culturelle en France (et, dans une moindre mesure, dans les pays anglo-saxons et l'Allemagne), avant d'en proposer une déclinaison prenant l'art comme objet et nourrie d'une double ambition: «que la géographie de l'art apporte sa contribution à la géographie en général, et particulièrement à la géographie urbaine, à la géographie culturelle et à la géographie sociale ; qu'elle apporte également sa contribution à la connaissance et à la compréhension des phénomènes artistiques » (p. 144).

13 « La géographie de l'art [proposée] est ambitieuse parce qu'elle interpelle (...) [et se] risque à apporter d'autres informations, d'autres interprétations, d'autres méthodes. Elle a le mérite de la nouveauté, même s'il lui reste à faire ses preuves " (p. 144). Gageons en tout cas que sa découverte intéressera les chercheurs en Belgique, par la façon qu'elle offre de renouveler les regards de la géographie sociale et urbaine à travers un objet de recherches singulier.

\section{NOTES}

1. GRESILLON B. (2008), «Ville et création artistique. Pour une autre approche de la géographie culturelle », Annales de géographie, 660-661, pp. 179-198

2. GRESILLON B. (2002), Berlin, métropole culturelle, Paris, Belin 